\title{
Experimental diabetes induces hyperreactivity of rabbit renal artery to 5-hydroxytryptamine
}

\author{
Francisco J. Miranda ${ }^{\mathrm{a}, *}$, José A. Alabadía, Silvia Lloréns ${ }^{\mathrm{a}}$, Rosa F. Ruiz de Apodaca ${ }^{\mathrm{a}}$, \\ José M. Centeno ${ }^{\mathrm{a}}$, Enrique Alborch ${ }^{\mathrm{a}, \mathrm{b}}$ \\ ${ }^{a}$ Departamento de Fisiología, Facultad de Farmacia, Universidad de Valencia, Avda. Vicente Andrés Estellés s/n, 46100 Burjassot, Valencia, Spain \\ ${ }^{\mathrm{b}}$ Centro de Investigación, Hospital La Fe, Valencia, Spain
}

Received 22 November 2001; received in revised form 15 February 2002; accepted 22 February 2002

\begin{abstract}
The influence of diabetes on the response of isolated rabbit renal arteries to 5-hydroxytryptamine (5-HT) was examined. 5-HT induced a concentration-related contraction that was higher in arteries from diabetic rabbits than in arteries from control rabbits. Endothelium removal did not significantly modify 5-HT contractions in arteries from control rabbits but enhanced the response to 5-HT in arteries from diabetic rabbits. Incubation with $N^{\mathrm{G}}$-nitro-L-arginine (L-NA) enhanced contractions to 5-HT in arteries from control and diabetic rabbits. In arteries with endothelium, this L-NA enhancement was lower in diabetic rabbits than in control rabbits. In arteries without endothelium, incubation with L-NA enhanced the maximal contractions to 5-HT in control rabbits but did not in diabetic rabbits. Indomethacin inhibited 5-HT-induced contraction of arteries from control rabbits and enhanced the maximal contraction to 5-HT of arteries from diabetic rabbits. In summary, diabetes enhances contractile response of rabbit renal artery to 5-HT. In control animals, this response is regulated by both endothelial and non-endothelial (neuronal) nitric oxide (NO) and by a vasoconstrictor prostanoid. Diabetes impairs the release of non-endothelial NO and the vasoconstrictor prostanoid. (C) 2002 Elsevier Science B.V. All rights reserved.
\end{abstract}

Keywords: Endothelium; Diabetes; Nitric oxide (NO); 5-HT (5-hydroxytryptamine, serotonin); Cyclooxygenase; Renal artery, rabbit

\section{Introduction}

Diabetic nephropathy is a leading cause of end-stage renal disease in the Western world, and its prevalence and incidence vary greatly from country to country, being highest in the United States and Japan. In the United States, diabetes is the underlying cause of about $40 \%$ of all kidney failure (Akmal, 2001). In Spain, diabetic nephropathy accounts for $30 \%$ of patients with renal failure (Caravaca et al., 2001). Diabetes is an independent risk factor for mortality in patients receiving peritoneal dialysis (Sancho et al., 2001) and increases the economic costs in dialysis with respect to the nondiabetic patients (Yang et al., 2001).

The endothelium contributes to the regulation of vascular reactivity through the release of different constrictor (angiotensin II, endothelin-1, thromboxane $\mathrm{A}_{2}$, prostaglandin $\mathrm{H}_{2}$ ) or relaxant [nitric oxide (NO), prostacyclin, endotheliumderived hyperpolarizing factor] substances, the equilibrium of which results in vascular tone. Changes in the regulatory

\footnotetext{
* Corresponding author. Tel.: +34-96-386-4903; fax: +34-96-398-3395.

E-mail address: francisco.j.miranda@uv.es (F.J. Miranda).
}

activity of endothelium have been implicated in the pathogenesis of diabetic nephropathy (Rabelink and Bakris, 1998). Immunohistochemical techniques show a reduced expression of NO synthase (NOS) in macula densa cells of diabetic kidneys (Yagihashi et al., 1996). In contrast, other studies suggest that excessive production of NO may contribute to renal hyperfiltration and hyperperfusion of diabetic nephropathy (Sugimoto et al., 1998; Choi et al., 1999). In addition, the observed increased renal production of thromboxane $\mathrm{A}_{2}$ and prostacyclin has claimed to be involved in the pathogenesis of renal diabetic damage (Okumura et al., 2000).

On the other hand, several reports suggest a possible role for 5-hydroxytryptamine (5-HT) in the pathophysiology of the renal diabetic complications. The reactivity of the renal vasculature towards 5-HT is changed in diabetic spontaneously hypertensive rats (Boston and Hodgson, 1997). Moreover, the fact that diabetes enhances plasma concentration of 5-HT and that 5-HT enhances the production of type IV collagen by human mesangial cells leads to suggest the involvement of 5-HT in the development of renal diabetic changes (Kasho et al., 1998). Finally, a clinical study 
achieved in non-insulin-dependent diabetes mellitus patients suggests the potential benefits of the use of the $5-\mathrm{HT}_{2}$ receptor antagonist sarpogrelate in the treatment of diabetic nephropathy (Ogawa et al., 1999).

We have recently described that experimental diabetes induces changes in endothelial-mediated relaxant responses of rabbit renal (Alabadí et al., 2001) and carotid (Miranda et al., 2000a) arteries. In addition, we have also reported that diabetes enhances the sensitivity of the rabbit carotid artery to 5-HT (Miranda et al., 2000b). The aim of the present study was to analyse diabetes-induced changes in the reactivity of the renal artery to 5-HT, including the study of the mechanisms that regulate this response. To do this, we studied the influence of alloxan-induced diabetes on modulatory mechanisms of the constrictor response of rabbit renal artery to 5-HT.

\section{Methods}

Thirty-eight male New Zealand white rabbits were used in the present study. Animals were randomly divided into two experimental groups: 20 in the control group and 18 destined for induction of experimental diabetes. Housing conditions and experimental procedures were in accordance with the European Union regulations on the use of animal for scientific purposes (86/609/EEC, Article 5, Appendix II) and promulgated by Spanish legislation on March 14, 1988 (R.D. 223/1988).

\subsection{Induction of diabetes and control animals}

For induction of experimental diabetes, rabbits weighing $2.0-3.2 \mathrm{~kg}$ were sedated with intramuscular $40 \mathrm{mg}$ of ketamine $\left(\operatorname{Ketolar}^{\circledR}\right)$. Diabetes was induced by injecting alloxan $\left(100 \mathrm{mg} \cdot \mathrm{kg}^{-1}\right)$ into the lateral ear vein. To prevent hypoglycaemia, $10 \mathrm{ml}$ of glucose $5 \%$ was injected (i.v.) after the alloxan and drinking water was supplemented with $10 \%$ glucose for the first $24 \mathrm{~h}$ after the alloxan injection. Thereafter, the animals were maintained on tap water and regular food ad libitum for 6 weeks. A second group of rabbits (2.1$3.0 \mathrm{~kg}$ ) was maintained under the same conditions for the same time period to serve as age-matched controls (henceforth "control rabbits"). Diabetic rabbits showed a marked increase in serum glucose and a failure to increase their body weight when compared with control rabbits. Table 1 shows the mean values of body weight and glycaemia before and 6 weeks after diabetes induction for the rabbits in the diabetic group and for the rabbits in the control group.

\subsection{Isometric tension recording}

Six weeks after diabetes induction, the diabetic and the age-matched control rabbits were anaesthetised with sodium thiopental (sodium pentothal, $2 \%$ i.v.) and killed by injection of potassium chloride $\left(10 \mathrm{mEq}, 0.5 \mathrm{ml} \cdot \mathrm{kg}^{-1}\right.$, i.v.). The renal
Table 1

Values of body weight and glycaemia in control and diabetic rabbits

\begin{tabular}{llll}
\hline & Body weight $(\mathrm{kg})$ & Glycaemia $(\mathrm{mM})$ & $n$ \\
\hline Control rabbits & & & \\
Initial time & $2.56 \pm 0.09$ & $5.9 \pm 0.2$ & 20 \\
6 weeks after & $3.58 \pm 0.07$ & $6.0 \pm 0.2$ & 20 \\
& & & \\
Diabetic rabbits & & $6.0 \pm 0.2$ & 18 \\
Initial time & $2.60 \pm 0.09$ & $20.7 \pm 1.3^{\mathrm{a}}$ & 18 \\
6 weeks after & $3.01 \pm 0.07^{\mathrm{a}}$ & &
\end{tabular}

Results are means \pm S.E.M.

${ }^{\text {a }}$ Significantly different from corresponding value in control rabbits, $p<0.05$.

arteries were dissected free and cut into cylindrical segments measuring 3-4 $\mathrm{mm}$ in length. Each segment was prepared for isometric tension recording in an organ bath. Two stainless steel L-shaped pins (diameter, $125 \mu \mathrm{m}$ ) were introduced through the arterial lumen. One pin was fixed to the organ bath wall and the other pin was connected to a strain gauge for isometric tension recording. The organ bath contained $5 \mathrm{ml}$ of Ringer-Locke solution that was bubbled continuously with $95 \% \mathrm{O}_{2}$ and $5 \% \mathrm{CO}_{2}$ to provide a $\mathrm{pH}$ of 7.3-7.4. Temperature was kept at $37^{\circ} \mathrm{C}$. A resting tension of $2 \mathrm{~g}$ was applied to the arterial segments, and they were allowed to equilibrate for a period of 60-90 min before the experiments were started. Tension was readjusted when necessary and the bath fluid was changed every $15 \mathrm{~min}$. After this period of equilibration, the reactivity of the arterial segments was checked by depolarisation with $50 \mathrm{mM} \mathrm{KCl}$.

\subsection{Concentration-response curves of 5-HT}

The experiments were carried out with renal arteries from both control and diabetic rabbits. Concentration-response curves for 5 -HT $\left(10^{-8}-3 \times 10^{-6} \mathrm{M}\right)$ were obtained by its cumulative addition to the organ bath. To assess the influence of the endothelium on the effect of 5-HT, concentration-response curves were obtained with arteries from which the endothelium had been removed by rubbing the intimal surface with a scored stainless steel rod (rubbed arteries). The absence of endothelium was examined by silver staining (Caplan and Schwartz, 1973). To assess the participation of $\mathrm{NO}$ in the response of renal arteries to 5-HT, the concentration-response curves for this amine were obtained after the incubation $(20 \mathrm{~min})$ of the unrubbed arteries with the inhibitor of NOS $N^{\mathrm{G}}$-nitro-L-arginine (LNA, $\left.10^{-4} \mathrm{M}\right)$. Moreover, concentration-response curves for 5-HT were obtained in rubbed arteries preincubated (20 $\min$ ) with $10^{-4} \mathrm{M}_{\mathrm{L}-\mathrm{NA}}$. The possibility that some arachidonic acid derivative could modulate the arterial response to 5-HT was examined by obtaining concentration-response curves for 5-HT after incubation $(20 \mathrm{~min})$ of the unrubbed arteries with indomethacin $\left(10^{-5} \mathrm{M}\right)$, an inhibitor of cyclooxygenase. Finally, we also obtained concentrationresponse curves for 5-HT in the presence of both L-NA $\left(10^{-4} \mathrm{M}\right)$ and indomethacin $\left(10^{-5} \mathrm{M}\right)$. 


\subsection{Drugs and solutions}

Alloxan, 5-HT and indomethacin were obtained from Sigma and L-NA from Peptide Institute. Alloxan was dissolved in saline solution. 5-HT and L-NA were dissolved in twice-distilled water and diluted in saline solution; the L-NA solution required sonication to dissolve completely. Indomethacin was dissolved in ethanol and diluted in saline solution. The composition of the Ringer-Locke solution was (mM): $\mathrm{NaCl}, 120 ; \mathrm{KCl}, 5.4 ; \mathrm{CaCl}_{2}, 2.2 ; \mathrm{MgCl}_{2}, 1.0$; $\mathrm{NaHCO}_{3}, 25$; and glucose, 5.6. To prepare the KCl-depolarising solution, $\mathrm{NaCl}$ was replaced by an equimolar amount of $\mathrm{KCl}$ in the normal Ringer-Locke solution.

\subsection{Statistical analysis}

Comparisons of body weight and glycaemia between control and diabetic rabbits were made by using unpaired Student's $t$-test. 5-HT-induced contractions are expressed as a percentage of the previous depolarisation induced by 50 $\mathrm{mM} \mathrm{KCl}$. For each concentration-response curve, the maximum effect $\left(E_{\max }\right)$ and the concentration of 5-HT that produced half of $E_{\max }\left(\mathrm{EC}_{50}\right)$ were calculated. Maximum effects are expressed as means \pm standard error of the mean (S.E.M.) and $\mathrm{EC}_{50}$ as the geometric mean with its confidence limits $(95 \%)$ for repeated experiments. Statistical comparisons of $E_{\max }$ and $-\log \mathrm{EC}_{50}\left(\mathrm{p} D_{2}\right)$ values between arteries from control and diabetic rabbits receiving the same experimental treatment were achieved by using unpaired Student's $t$-test. Comparisons between the values of $E_{\max }$ and $\mathrm{p} \mathrm{D}_{2}$ of the concentration-response curves for 5-HT obtained with the different treatments in the arteries from the control rabbits were made using analysis of variance (ANOVA) followed by the Newman-Keuls test. The same tests were used to compare $E_{\max }$ and $\mathrm{p} D_{2}$ values of the curves obtained with the different treatments in the arteries from diabetic rabbits. A probability value of less than $5 \%$ was considered significant.

\section{Results}

Exposure of arterial segments from control rabbits to 50 $\mathrm{mM} \mathrm{KCl}$ induced a contractile response $(8187 \pm 1057 \mathrm{mg})$ that was not significantly different from that obtained in renal arterial segments from diabetic rabbits $(8092 \pm 1133 \mathrm{mg})$.

5 -HT $\left(10^{-8}-3 \times 10^{-6} \mathrm{M}\right)$ induced concentrationrelated contractions of the renal artery from either control or diabetic rabbits (Fig. 1). The maximal contraction obtained was significantly higher in arteries from diabetic rabbits with respect to that obtained in arteries from control rabbits, without significant differences between $\mathrm{EC}_{50}$ values (Table 2).

In arteries from control rabbits, mechanical removal of the endothelium did not significantly modify the $E_{\max }$ nor $\mathrm{EC}_{50}$ values of the concentration-response curve to 5-HT (Fig. 1; Table 2). In arteries from diabetic rabbits, mechanical

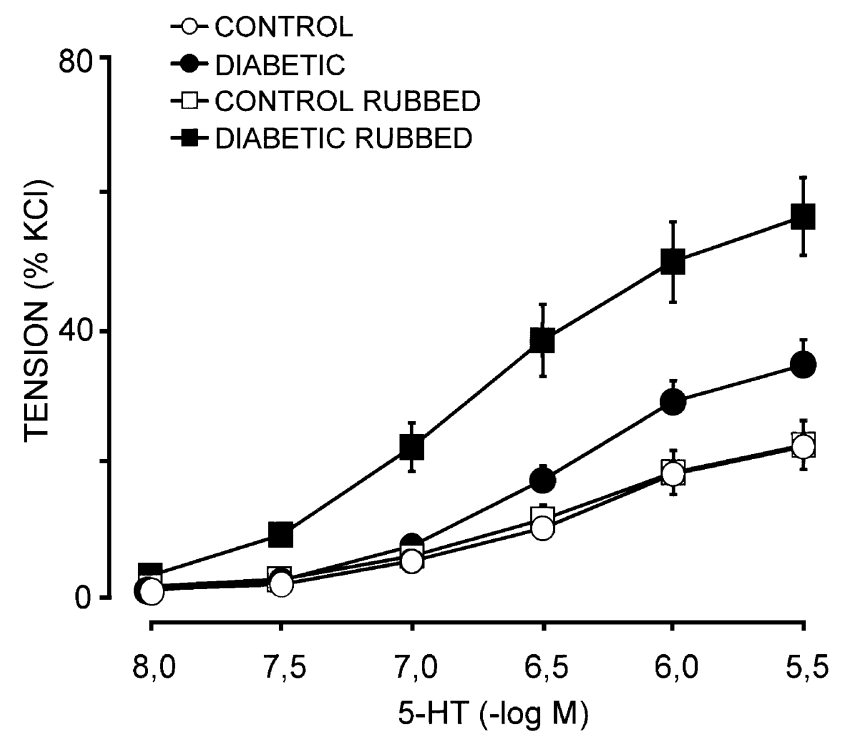

Fig. 1. Concentration-response contractile curves for 5-HT in renal arteries isolated from control (open symbols) and diabetic (solid symbols) rabbits in arteries with (circles) and without (squares) endothelium. Values represent means + S.E.M.

removal of the endothelium displaced to the left and strongly enhanced the $E_{\max }$ value of the concentration-response curve for 5-HT (Fig. 1; Table 2), being the maximal contraction significantly higher with respect to that obtained in rubbed arteries from control rabbits (Table 2).

In arteries with endothelium, incubation with L-NA $\left(10^{-4} \mathrm{M}\right)$ enhanced the contractions induced by 5 -HT in arterial segments from either control or diabetic rabbits, without significant differences between $\mathrm{EC}_{50}$ values (Fig. 2; Table 2). The maximal contraction to 5-HT in L-NA-treated arteries from diabetic animals was significantly lower than that obtained in arterial segments from control rabbits (Fig. 2; Table 2).

In arteries from control animals, the $E_{\max }$ value to 5-HT of L-NA-treated arterial segments was also significantly higher with respect to that obtained in rubbed arteries (Table 2). In arteries from diabetic rabbits, the contractile response induced by 5-HT in the presence of L-NA was not significantly different with respect to that obtained in rubbed arteries (Table 2).

In L-NA- $\left(10^{-4} \mathrm{M}\right)$ pretreated rubbed renal arteries isolated from control rabbits, 5-HT induced a concentration-dependent contraction with an $\mathrm{EC}_{50}$ significantly lower than that obtained in control arteries, and a maximal contraction significantly higher with respect to both control and rubbed arteries but significantly lower with respect to L-NA unrubbed arteries (Fig. 2; Table 2).

In arteries from diabetic rabbits, incubation of rubbed segments with L-NA $\left(10^{-4} \mathrm{M}\right)$ induced a significant enhancement of the contractile response to 5-HT with respect to their corresponding control, without significant differences with respect to either rubbed or L-NA-treated arterial segments (Fig. 2; Table 2). The contractile response induced by 
Table 2

$\mathrm{EC}_{50}$ and maximum effect $\left(E_{\max }\right)$ values for concentration-response curves to 5-hydroxytryptamine in rabbit renal artery

\begin{tabular}{|c|c|c|c|}
\hline Control rabbits & $\mathrm{EC}_{50}\left(\times 10^{-7} \mathrm{M}\right)$ & $E_{\max }(\%)$ & $n$ \\
\hline Control & $3.4(3.1-3.7)$ & $22 \pm 3$ & 23 \\
\hline Rubbed & $2.7(2.3-3.1)$ & $22 \pm 4$ & 21 \\
\hline L-NA $10^{-4} \mathrm{M}$ & $2.6(2.2-2.9)$ & $69 \pm 7^{\mathrm{a}, \mathrm{b}}$ & 12 \\
\hline Rubbed + L-NA $10^{-4} \mathrm{M}$ & $1.7(1.4-2.2)^{\mathrm{a}}$ & $39 \pm 11^{\mathrm{a}, \mathrm{b}, \mathrm{c}}$ & 6 \\
\hline Indomethacin $10^{-5} \mathrm{M}$ & $4.1(3.6-4.6)$ & $9 \pm 2^{\mathrm{a}, \mathrm{b}, \mathrm{c}}$ & 15 \\
\hline $\begin{array}{l}\text { L-NA } 10^{-4} \mathrm{M}+ \\
\quad \text { indomethacin } 10^{-5} \mathrm{M}\end{array}$ & $2.6(2.2-2.9)$ & $50 \pm 5^{\mathrm{a}, \mathrm{b}, \mathrm{c}, \mathrm{d}}$ & 10 \\
\hline Diabetic rabbits & $\mathrm{EC}_{50}\left(\times 10^{-7} \mathrm{M}\right)$ & $E_{\max }(\%)$ & $n$ \\
\hline Control & $3.2(2.9-3.5)$ & $34 \pm 4^{\mathrm{e}}$ & 20 \\
\hline Rubbed & $1.9(1.7-2.2)^{\mathrm{a}}$ & $56 \pm 6^{\mathrm{a}, \mathrm{e}}$ & 19 \\
\hline L-NA $10^{-4} \mathrm{M}$ & $2.8(2.5-3.1)$ & $48 \pm 4^{\mathrm{a}, \mathrm{e}}$ & 15 \\
\hline Rubbed + L-NA $10^{-4} \mathrm{M}$ & $2.7(2.5-2.9)$ & $52 \pm 9^{a}$ & 12 \\
\hline Indomethacin $10^{-5} \mathrm{M}$ & $2.6(2.1-3.2)^{\mathrm{e}}$ & $52 \pm 4^{\mathrm{a}, \mathrm{e}}$ & 7 \\
\hline $\begin{array}{l}\text { L-NA } 10^{-4} \mathrm{M}+ \\
\quad \text { indomethacin } 10^{-5} \mathrm{M}\end{array}$ & $1.9(1.5-2.6)$ & $50 \pm 7$ & 9 \\
\hline
\end{tabular}

$\overline{E_{\max } \text { values are expressed as a percentage of a previous depolarisation with }}$ $\mathrm{KCl} 50 \mathrm{mM}$. $\mathrm{EC}_{50}$ values are means and confidence limits; $E_{\max }$ values are means \pm S.E.M.; $n$ : number of arterial segments.

a Significantly different from corresponding control value, $p<0.05$.

b Significantly different from corresponding rubbed value, $p<0.05$

c Significantly different from corresponding L-NA $10^{-4} \mathrm{M}$ value, $p<0.05$.

${ }^{\mathrm{d}}$ Significantly different from corresponding indomethacin $10^{-5} \mathrm{M}$ value, $p<0.05$.

e Significantly different from corresponding value in control rabbits, $p<0.05$.

5-HT in rubbed arteries preincubated with L-NA from diabetic animals was not significantly different with respect to the contraction obtained in arteries with the same experimental treatment from control rabbits (Table 2).

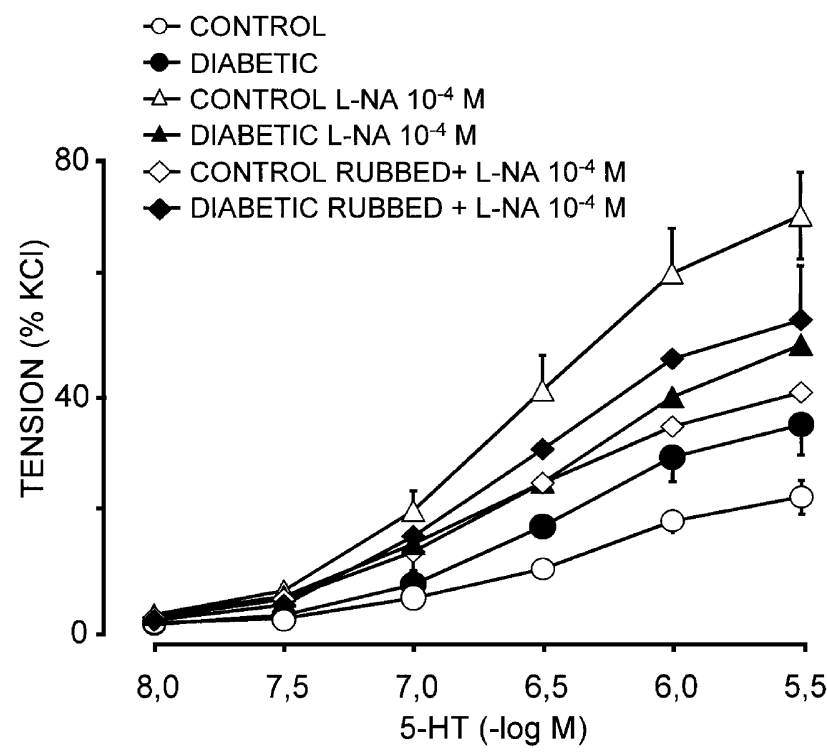

Fig. 2. Concentration-response contractile curves for 5-HT in renal arteries isolated from control (open symbols) and diabetic (solid symbols) rabbits in different experimental conditions: control (circles), incubated with L-NA $10^{-4} \mathrm{M}$ (triangles), and both rubbed and incubated with L-NA $10^{-4} \mathrm{M}$ (diamonds). Values represent means \pm S.E.M.

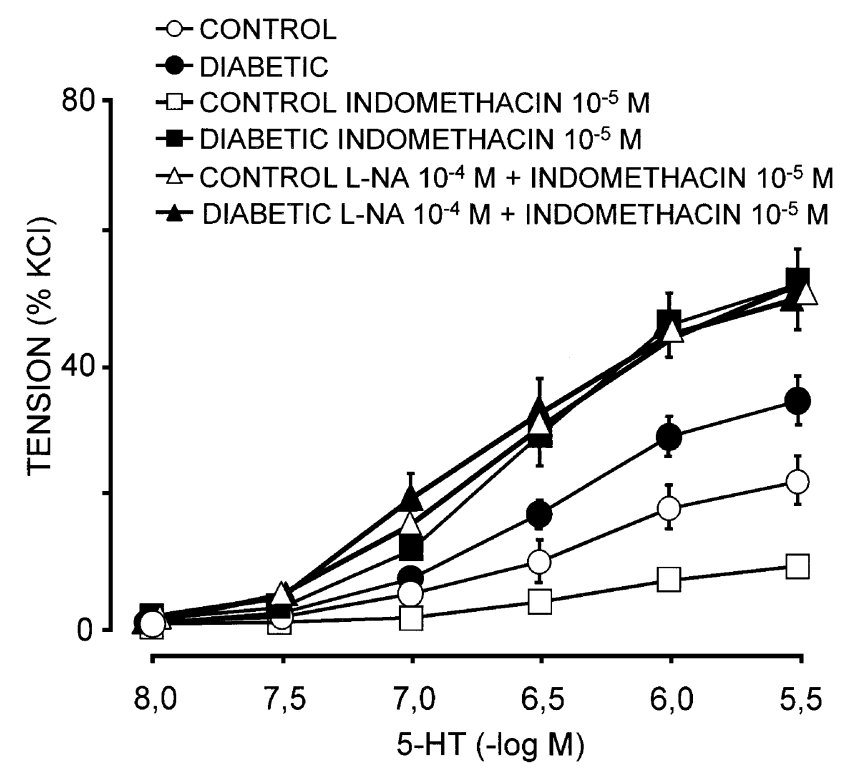

Fig. 3. Concentration-response contractile curves for 5-HT in renal arteries isolated from control (open symbols) and diabetic (solid symbols) rabbits in different experimental conditions: control (circles), incubated with indomethacin $10^{-5} \mathrm{M}$ (squares), and incubated with both L-NA $10^{-4} \mathrm{M}$ and indomethacin $10^{-5} \mathrm{M}$ (triangles). Values represent means \pm S.E.M.

In arteries from control rabbits, pretreatment of arterial segments with indomethacin $\left(10^{-5} \mathrm{M}\right)$ significantly inhibited the $E_{\max }$ of the concentration-response contractile curve for 5-HT, without affecting the $\mathrm{EC}_{50}$ value (Fig. 3; Table 2). In the presence of both L-NA $\left(10^{-4} \mathrm{M}\right)$ and indomethacin $\left(10^{-5} \mathrm{M}\right)$, the concentration-response curve for 5-HT exhibited an $E_{\max }$ significantly higher than that obtained both in control and indomethacin-treated arteries and significantly lower than that obtained in L-NA-treated arteries, without significant differences between $\mathrm{EC}_{50}$ values (Fig. 3; Table 2).

In arteries from diabetic rabbits, incubation with indomethacin $\left(10^{-5} \mathrm{M}\right)$ significantly enhanced the maximal contraction to 5-HT (Fig. 3; Table 2). The $E_{\max }$ and $\mathrm{EC}_{50}$ values of the concentration-response curve for 5-HT obtained in the presence of both L-NA $\left(10^{-4} \mathrm{M}\right)$ and indomethacin $\left(10^{-5} \mathrm{M}\right)$ were not significantly different with respect to the other experimental situations in diabetic rabbits (Fig. 3; Table 2).

\section{Discussion}

In this work, we have studied the influence of alloxaninduced diabetes on the modulatory mechanisms of rabbit renal arterial constrictor response to 5-HT. To do this, we have used an experimental model of chemical diabetes in the rabbit. The diabetogenic agent used was alloxan. This drug induces in the animal a syndrome resembling type-I diabetes mellitus, characterised by hyperglycaemia, hypercholesterolemia, glycosuria and raised levels of glycosylated hemoglobin in erythrocytes (Agrawal et al., 1987), and it is 
accepted as a valid experimental model of diabetes in the rabbit (Öztürk et al., 1996).

The present results show that 5-HT contracted renal arteries isolated from control and diabetic rabbits. In arteries from diabetic rabbits, this contraction was higher than that obtained in arteries from control animals. This would be in agreement with the diabetes enhancement of the pressor response to 5-HT in pulmonary circulation (El Kashef, 1996) and the enhanced sensitivity of basilar (Van Buren et al., 1998) and carotid (Miranda et al., 2000b) artery to 5HT observed in diabetic animals. Diabetes also enhances the renal vasoconstrictor effect of adenosine (Pflueger et al., 1999). In contrast, other studies describe that diabetes reduces the contractile response of the rat aorta to 5-HT (James et al., 1994; James and Hodgson, 1997).

In arteries from control rabbits, the mechanical removal of the endothelium did not significantly modify the concentration-response curve to 5-HT. This result is in accordance with studies showing that the contractile responses to 5 -HT of bovine anterior ciliary artery (Buckley et al., 1998) and human deferential artery (Medina et al., 1996) were unaffected by removal of the endothelium. However, it has been observed that the endothelium partially counteracts the contractile response to 5-HT in goat middle cerebral artery (Miranda et al., 1993), rabbit saphenous vein (Valentin et al., 1996), human uterine artery (Karlsson et al., 1998) and rabbit carotid artery (Miranda et al., 2000b). The present result would suggest either that the endothelium does not modulate the contractile response of the renal artery to 5-HT or, more probably, that there is equilibrium between endothelium-released vasodilators and vasoconstrictors. In contrast, in arterial segments from diabetic animals, the removal of the endothelium induced an enhancement of the 5-HTinduced contraction. This result shows that the endothelium inhibits the 5-HT-induced contraction of renal arteries from diabetic rabbits. Diabetes enhances the inhibitory activity of the endothelium on 5-HT-induced contractions in rabbit carotid artery (Miranda et al., 2000b). Diabetes also enhances the endothelium-dependent relaxations to histamine (White and Carrier, 1986) and to acetylcholine (Bhardwaj and Moore, 1988; Pieper, 1999; Alabadí et al., 2001). In addition, the fact that in diabetic arteries without endothelium the 5-HT-induced contraction was higher than that obtained in control rabbits would suggest the existence of a diabetes-induced hyperreactivity of the renal arterial smooth muscle to 5-HT that would be partially deadened by the enhanced modulatory activity of the endothelium.

We have investigated the participation of $\mathrm{NO}$ in the modulatory action of the endothelium in the 5-HT-induced response of renal artery from either control or diabetic rabbits. NO is synthesised from the amino acid L-arginine by the $\mathrm{Ca}^{2+}$-dependent enzyme NOS. There are three isoenzymes of NOS (Moncada et al., 1997): two constitutive isoforms, endothelial (eNOS) and neuronal (nNOS), and one inducible (iNOS). Incubation of renal arteries from either control or diabetic rabbits with the inhibitor of the constitutive NOS L-
NA significantly enhanced the contractile response of arterial segments to 5-HT. This indicates that in the presence of 5-HT, renal arterial endothelium releases NO that partially counteracts the contractile response to this amine. This is in agreement with data obtained in cerebral (Miranda et al., 1993), pulmonary (Shi et al., 1998) and carotid (Miranda et al., 2000 b) arteries. The maximal contraction induced by 5-HT in the presence of L-NA was significantly lower in renal arteries from diabetic rabbits than in those from control rabbits, thus suggesting that $\mathrm{NO}$ was less effective at inhibiting diabetic than control arteries, indicating a lower modulatory role of $\mathrm{NO}$ in the diabetic state. Previously, we have reported that the arterial response induced by the NO donor sodium nitroprusside is similar in renal arteries from control and diabetic rabbits, thus indicating that the sensitivity of smooth muscle cells of renal arteries to $\mathrm{NO}$ is not altered in our diabetic rabbits (Alabadí et al., 2001).

In arteries from control rabbits, the 5-HT-induced contraction in rubbed arterial segments preincubated with L-NA was significantly higher than that obtained in rubbed arteries in the absence of the inhibitor. This would suggest that NO is released from a non-endothelial (neuronal) NO source as well as from endothelium in response to 5-HT, in a similar way as described in the responses of the goat middle cerebral artery to 5-HT (Miranda et al., 1996) and endothelin-1 (Alabadí et al., 1997). In carotid and cerebral arteries, vasodilator perivascular nerves that synthesise and release NO by means of nNOS have been identified (Tomimoto et al., 1994; Ignacio et al., 1997). NO derived from nNOS plays a role in the control of systemic and renal hemodynamics in the rat (Komers et al., 2000a,b). Therefore, this nitric oxidergic perivascular nerve source might be the responsible of the endothelium-independent modulatory mechanisms described above in the response of the rabbit renal artery to 5-HT. The absence, in diabetic rabbits, of significant differences between the contractions to 5-HT in rubbed arteries without L-NA and rubbed arteries preincubated with L-NA suggests an impairment of the non-endothelial source of NO in diabetes. This impairment could be, at least partially, responsible of the hyperreactivity of the renal artery to 5-HT in diabetes. A defective NO-dependent renal vasodilation is responsible of the increased vasoconstrictor sensitivity of the diabetic renal vasculature to adenosine (Pflueger et al., 1999). Diabetes is associated with a reduction of nNOS activity in retinal vasculature (Roufail et al., 1998), skeletal muscle (Perreault et al., 2000), mesenteric artery (Ferrer et al., 2000) and penile tissue (Cellek et al., 1999) of the streptozotocin-induced diabetic rats. In contrast, an increased activity of the nNOS pathway has been suggested to play a role in the pathogenesis of diabetic renal hemodynamic changes in the rat (Komers et al., 2000a,b).

In control rabbits, the maximal contraction induced by 5 HT in L-NA-treated unrubbed arteries was significantly higher than that obtained in rubbed arteries preincubated with the inhibitor. This result suggests that, in control 
animals, endothelium modulates renal arterial response to 5HT through the release of both $\mathrm{NO}$ and a vasoconstrictor. When NO synthesis had been inhibited but not that of the vasoconstrictor (unrubbed arteries incubated with L-NA), the maximal tension reached was higher with respect to contraction obtained in L-NA-treated rubbed arteries, in which both NO and the vasoconstrictor had been removed. Moreover, the inhibitor of the enzyme cyclooxygenase indomethacin (Moncada and Vane, 1979) significantly inhibited the contraction induced by 5 -HT, thus suggesting the prostanoid nature of the endothelial vasoconstrictor (i.e. thromboxane $\mathrm{A}_{2}$ ). A similar result has been obtained in human umbilical artery (De Moraes et al., 1997; Mathias et al., 1997), guinea-pigs pulmonary veins (Shi et al., 1998) and rabbit carotid artery (Miranda et al., 2000b).

In contrast with results obtained in arteries from control rabbits, in diabetic rubbed renal arteries incubated with L-NA, the contraction induced by 5-HT was not significantly different from that obtained with each of these two treatments (removal of endothelium and incubation with L-NA) by separate. This would suggest that diabetes impairs the participation of the endothelial vasoconstrictor prostanoid. Moreover, the incubation of diabetic arterial segments with indomethacin enhanced the contractile response to 5-HT, thus suggesting that the endothelial arachidonic acid derivative of the cyclooxygenase via in diabetic arteries has vasodilator influence (probably prostacyclin). Our results are in agreement with the decreased activity of vasoconstrictor prostanoids (Makino and Kamata, 1998; Miranda et al., 2000a,b) and the enhanced activity of vasodilator prostanoids (Okumura et al., 2000; Alabadí et al., 2001) that have been reported in diabetes. It could be hypothesised that, in the experimental conditions of the present study, the absence of the vasoconstrictor prostanoid would be the expression of a compensatory mechanism addressed to minimise the deleterious consequences of both the hyperreactivity of renal artery to 5-HT and the defective participation of NO.

In conclusion, diabetes enhances contractile response of rabbit renal artery to 5-HT. In control animals, this response is regulated by both endothelial and non-endothelial (neuronal) NO and by a vasoconstrictor prostanoid. Diabetes impairs the release of non-endothelial NO and the vasoconstrictor prostanoid.

\section{Acknowledgements}

The authors are grateful to Salvador Banacloche for his technical assistance.

\section{References}

Agrawal, D.K., Bhimji, S., Mcneill, J.H., 1987. Effect of chronic experimental diabetes on vascular smooth muscle function in rabbit carotid artery. J. Cardiovasc. Pharmacol. 9, 584-593.

Akmal, M., 2001. Hemodialysis in diabetic patients. Am. J. Kidney Dis. 38 (Suppl. 1), S195-S199.
Alabadí, J.A., Torregrosa, G., Miranda, F.J., Salom, J.B., Centeno, J.M., Alborch, E., 1997. Impairment of the modulatory role of nitric oxide on the endothelin-1-elicited contraction of cerebral arteries: a pathogenetic factor in cerebral vasospasm after subarachnoid hemorrhage? Neurosurgery $41,245-253$.

Alabadí, J.A., Miranda, F.J., Lloréns, S., Ruiz de Apodaca, R.F., Centeno, J.M., Alborch, E., 2001. Diabetes potentiates acetylcholine-induced relaxation in rabbit renal arteries. Eur. J. Pharmacol. 415, 225-232.

Bhardwaj, R., Moore, P.K., 1988. Increased vasodilator response to acetylcholine of renal blood vessels from diabetic rats. J. Pharm. Pharmacol. 40, 739-742.

Boston, P.C., Hodgson, W.C., 1997. Changes in the reactivity towards 5hydroxytryptamine in the renal vasculature of the diabetic spontaneously hypertensive rat. J. Hypertens. 15, 769-774.

Buckley, C.H., Hadoke, P.W., O'Brien, C.J., 1998. Role of the endothelium in modulating functional responses of isolated bovine anterior ciliary arteries to vasoconstrictor agonists. Br. J. Ophthalmol. 82, 826-829.

Caplan, B.A., Schwartz, C.J., 1973. Increased endothelial cell turnover in areas of in vivo Evans Blue uptake in the pig aorta. Atherosclerosis 17, $401-417$.

Caravaca, F., Arrobas, M., Pizarro, J.L., Cancho, B., Cubero, J.J., Espárrago, J.F., García, M.C., Sanchez-Casado, E., 2001. Predictors of early death during dialysis. Nefrologia 21, 274-282.

Cellek, S., Rodrigo, J., Lobos, E., Fernández, P., Serrano, J., Moncada, S., 1999. Selective nitrergic neurodegeneration in diabetes mellitus - a nitric oxide-dependent phenomenon. Br. J. Pharmacol. 128, 18041812.

Choi, K.C., Lee, S.C., Kim, S.W., Kim, N.H., Lee, J.U., Kang, Y.J., 1999. Role of nitric oxide in the pathogenesis of diabetic nephropathy in streptozotocin-induced diabetic rats. Korean J. Intern. Med. 14, 32-41.

De Moraes, S., Cavalcante, M.T., Carvalho, J.C., Mathias, R.S., 1997. Endogenous thromboxane $\mathrm{A}_{2}$ does not contribute to the contractile response of human umbilical artery strips to 5-hydroxytryptamine. Gen. Pharmacol. 29, 783-787.

El Kashef, H., 1996. Hyperglycemia increased the responsiveness of isolated rabbit's pulmonary arterial rings to serotonin. Pharmacology 53, $151-159$.

Ferrer, M., Marín, J., Balfagón, G., 2000. Diabetes alters neuronal nitric oxide release from rat mesenteric arteries. Role of protein kinase C. Life Sci. 66, 337-345.

Ignacio, C.S., Curling, P.E., Childres, W.F., Brian Jr., R.M., 1997. Nitric oxide-synthesizing perivascular nerves in the rat middle cerebral artery. Am. J. Physiol. 273, R661-R668.

James, G.M., Hodgson, W.C., 1997. A role for protein kinase C in attenuated response to 5-hydroxytryptamine in aortas from streptozotocindiabetic rats. Eur. J. Pharmacol. 322, 55-58.

James, G.M., Hodgson, W.C., Davis, E.A., Haynes, J.M., 1994. Attenuated 5-hydroxytryptamine receptor-mediated responses in aortae from streptozotocin-induced diabetic rats. Br. J. Pharmacol. 111, 370-376.

Karlsson, C., Bodelsson, G., Bodelsson, M., Stjernquist, M., 1998. Endothelium-derived prostanoids reduce 5-hydroxytryptamine-induced contraction in the human uterine artery. Hum. Reprod. 13, 1947-1951.

Kasho, M., Sakai, M., Sasahara, T., Anami, Y., Matsumura, T., Takemura, T., Matsuda, H., Kobori, S., Shichiri, M., 1998. Serotonin enhances the production of type IV collagen by human mesangial cells. Kidney Int. 54, 1083-1092.

Komers, R., Lindsley, J.N., Oyama, T.T., Allison, K.M., Anderson, S., 2000a. Role of neuronal nitric oxide synthase (NOS1) in the pathogenesis of renal hemodynamic changes in diabetes. Am. J. Physiol. 279, F573-F583.

Komers, R., Oyama, T.T., Chapman, J.G., Allison, K.M., Anderson, S., 2000b. Effects of systemic inhibition of neuronal nitric oxide synthase in diabetic rats. Hypertension 35, 655-661.

Makino, A., Kamata, K., 1998. Possible modulation by endothelin-1, nitric oxide, prostaglandin $\mathrm{I}_{2}$ and thromboxane $\mathrm{A}_{2}$ of vasoconstriction induced by an alpha-agonist in mesenteric arterial bed from diabetic rats. Diabetologia 41, 1410-1418. 
Mathias, R.S., Carvalho, J.C., Cavalcante, M.T., De Moraes, S., 1997. Effects of simulated myocardial ischemic conditions on the responses of isolated human umbilical artery strips to 5-hydroxytryptamine and prostaglandin $\mathrm{F}_{2}$ alpha. Gen. Pharmacol. 29, 483-487.

Medina, P., Chuan, P., Noguera, R., Vila, J.M., Aldasoro, M., Lluch, S., 1996. Reactivity of human deferential artery to constrictor and dilator substances. J. Androl. 17, 733-739.

Miranda, F.J., Torregrosa, G., Salom, J.B., Alabadí, J.A., Jover, T., Barberá, M.D., Alborch, E., 1993. Endothelial modulation of 5-hydroxytryptamine-induced contraction in goat cerebral arteries. Gen. Pharmacol. 24, 649-653.

Miranda, F.J., Alabadí, J.A., Torregrosa, G., Salom, J.B., Jover, T., Barberá, M.D., Alborch, E., 1996. Modulatory role of endothelial and nonendothelial nitric oxide in 5-hydroxytryptamine-induced contraction in cerebral arteries after subarachnoid hemorrhage. Neurosurgery 39, $998-$ 1004.

Miranda, F.J., Alabadí, J.A., Llorens, S., Ruiz de Apodaca, R.F., Centeno, J.M., Alborch, E., 2000a. Influence of experimental diabetes on regulatory mechanisms of vascular response of rabbit carotid artery to acetylcholine. Life Sci. 66, 2071-2080.

Miranda, F.J., Alabadí, J.A., Llorens, S., Ruiz de Apodaca, R.F., Centeno, J.M., Alborch, E., 2000b. Diabetes-induced changes in endothelial mechanisms implicated in rabbit carotid arterial response to 5-hydroxytryptamine. Eur. J. Pharmacol. 401, 397-402.

Moncada, S., Vane, J.R., 1979. Pharmacology and endogenous roles of prostaglandin endoperoxides, thromboxane $\mathrm{A}_{2}$, and prostacyclin. Pharmacol. Rev. 30, 293-331.

Moncada, S., Higgs, A., Furchgott, R., 1997. XIV International Union of Pharmacology Nomenclature in nitric oxide research. Pharmacol. Rev. $49,137-142$.

Ogawa, S., Takeuchi, K., Sugimura, K., Sato, C., Fukuda, M., Lee, R., Ito, S., Sato, T., 1999. The $5-\mathrm{HT}_{2}$ receptor antagonist sarpogrelate reduces urinary and plasma levels of thromboxane $\mathrm{A}_{2}$ and urinary albumin excretion in non-insulin-dependent diabetes mellitus patients. Clin. Exp. Pharmacol. Physiol. 26, 461-464.

Okumura, M., Imanishi, M., Yamashita, T., Yamamura, Y., Kim, S., Iwao, H., Tanaka, S., Fujii, S., 2000. Renal production of thromboxane and prostaglandins in a rat model of type 2 diabetes. Life Sci. 66, 371-377.

Öztürk, Y., Altan, V.M., Yildizoğlu-Ari, N., 1996. Effects of experimental diabetes and insulin on smooth muscle functions. Pharmacol. Rev. 48, $69-110$.

Perreault, M., Dombrowski, L., Marette, A., 2000. Mechanism of impaired nitric oxide synthase activity in skeletal muscle of streptozotocin-induced diabetic rats. Diabetologia 43, 427-437.

Pflueger, A.C., Osswald, H., Knox, F.G., 1999. Adenosine-induced renal vasoconstriction in diabetes mellitus rats: role of nitric oxide. Am. J. Physiol. 276, F340-F346.

Pieper, G.M., 1999. Enhanced, unaltered and impaired nitric oxide mediated endothelium-dependent relaxation in experimental diabetes mellitus: importance of disease duration. Diabetologia 42, 204-213.

Rabelink, T.J., Bakris, G.L., 1998. The renin-angiotensin system in diabetic nephropathy: the endothelial connection. Miner. Electrolyte Metab. 24, 381-388

Roufail, E., Soulis, T., Boel, E., Cooper, M.E., Rees, S., 1998. Depletion of nitric oxide synthase-containing neurons in the diabetic retina: reversal by aminoguanidine. Diabetologia 41, 1419-1425.

Sancho, A., Perez Ruixo, J.J., Gorriz, J.L., Miguel, A., Garcia Ramon, R., Avila, A., 2001. Risk factors associated with survival in patients in a peritoneal dialysis program. Nefrologia 21, 160-166.

Shi, W., Wang, C.G., Dandurand, R.J., Eidelman, D.H., Michel, R.P., 1998. Differential responses of pulmonary arteries and veins to histamine and 5-HT in lung explants of guinea-pigs. Br. J. Pharmacol. 123, 15251532 .

Sugimoto, H., Shikata, K., Matsuda, M., Kushiro, M., Hayashi, Y., Hiragushi, K., Wada, J., Makino, H., 1998. Increased expression of endothelial cell nitric oxide synthase (ecNOS) in afferent and glomerular endothelial cells is involved in glomerular hyperfiltration of diabetic nephropathy. Diabetologia 41, 1426-1434.

Tomimoto, H., Nishimura, M., Suenaga, T., Nakamura, S., Akiguchi, I., Wakita, H., Kimura, J., Mayer, B., 1994. Distribution of nitric oxide synthase in the human cerebral blood vessels and brain tissues. J. Cereb. Blood Flow Metab. 14, 930-938.

Valentin, J.P., Bonnafous, R., John, G.W., 1996. Influence of the endothelium and nitric oxide on the contractile responses evoked by $5-\mathrm{HT}_{1 \mathrm{D}}$ receptor agonists in the rabbit isolated saphenous vein. Br. J. Pharmacol. $119,35-42$.

Van Buren, T., Vleeming, W., Krutzen, M.M., Van De Kuil, T., Gispen, W.H., De Wildt, D.J., 1998. Vascular responses of isolated mesenteric resistance and basilar arteries from short- and long-term diabetic rats. Naunyn-Schmiedeberg's Arch. Pharmacol. 358, 663-670.

White, R.O., Carrier, G.O., 1986. Supersensitivity and endothelium dependency of histamine-induced relaxation in mesenteric arteries isolated from diabetic rats. Pharmacology 33, 34-38.

Yagihashi, N., Nishida, N., Geuk Seo, H., Taniguchi, N., Yagihashi, S., 1996. Expression of nitric oxide synthase in macula densa in streptozotocin diabetic rats. Diabetologia 39, 793-799.

Yang, W., Hwang, S., Chiang, S., Chen, H., Tsai, S., 2001. The impact of diabetes on economic costs in dialysis patients: experiences in Taiwan. Diabetes Res. Clin. Pract. 54 (Suppl. 1), 47-54. 